Original Research Paper

\title{
Prediction of Body Weight from Linear Body Measurement Traits of Boer Goats Raised at Farm Tivolie, Limpopo Province, South Africa
}

\author{
${ }^{1}$ Lebo Trudy Rashijane, ${ }^{2}$ Vusi G Mbazima and ${ }^{1}$ Thobela Louis Tyasi \\ ${ }^{1}$ School of Agricultural and Environmental Sciences, Department of Agricultural Economics and Animal Production, \\ University of Limpopo, Private Bag X1106, Sovenga 0727, Limpopo, South Africa \\ ${ }^{2}$ School of Molecular and Life Sciences, Department of Biochemistry Microbiology and Biotechnology, \\ Private Bag X1106, Sovenga 0727, Limpopo, South Africa
}

\author{
Article history \\ Received: 15-06-2021 \\ Revised: 27-07-2021 \\ Accepted: 11-08-2021 \\ Corresponding Author: \\ Thobela Louis Tyasi \\ School of Agricultural and \\ Environmental Sciences, \\ Department of Agricultural \\ Economics and Animal \\ Production, University of \\ Limpopo, Private Bag X1106, \\ Sovenga 0727, Limpopo, South \\ Africa \\ E-mail: louis.tyasi@ul.ac.za
}

\begin{abstract}
A total of 72 Boer goats (females $=58$ and males $=14$ ) from the age of one to five years were used to determine the association between Body Weight (BW) and linear body measurement traits viz. Body Length (BL), Heart Girth (HG), Rump Height (RH), Rump Width (RW), Ear Length (EL), Cannon Circumference (CC) and Heard Width (HW) and to establish a model for the prediction of BW using linear body measurement traits. Pearson correlation results indicated that BW in Boer goats had a positively high statistically association $(\mathrm{P}<0.01)$ with $\mathrm{BL}\left(\mathrm{r}=0.86^{* *}\right), \mathrm{HG}\left(\mathrm{r}=0.89^{* *}\right)$, $\mathrm{RH}\left(\mathrm{r}=0.75^{* *}\right), \mathrm{CC}\left(\mathrm{r}=0.58^{* *}\right)$ and $\mathrm{HW}\left(\mathrm{r}=0.65^{* *}\right)$. Furthermore, the results showed that $\mathrm{BW}$ in bucks had a positively high statistical correlation $(\mathrm{P}<0.01)$ with BL $\left(\mathrm{r}=0.62^{* *}\right), \mathrm{HG}\left(\mathrm{r}=0.83^{* *}\right), \mathrm{RH}\left(\mathrm{r}=0.56^{* *}\right)$ and HW $\left(\mathrm{r}=0.51^{* *}\right)$ and a positive statistical correlation $(\mathrm{P}<0.05)$ with $\mathrm{RW}(\mathrm{r}=$ $\left.0.31^{*}\right)$ and $\mathrm{CC}\left(\mathrm{r}=0.36^{*}\right)$, as well as a negative statistical association $(\mathrm{P}<0.05)$ with EL $\left(\mathrm{r}=-0.25^{*}\right)$. The regression results suggest that improving $\mathrm{BL}$ and $\mathrm{HG}$ might result in the improvement of BW in Boer goats.
\end{abstract}

Keywords: Body Weight, Correlation, Regression, Heart Girth, Body Length

\section{Introduction}

Goats are one of the oldest domestic species that are known to be to be a dormant genetic source of fibre, meat, milk and skin (Atoui et al., 2017). These animals are resistant to diseases, adapt well to unfavourable weather and have low-value feed acceptance (Monteiro et al., 2017). The use of linear body measurements is important in defining performance in livestock and associations among body measurements and performance traits (Cam et al., 2010). Shirzeyli et al. (2013), states that knowing the bodyweight of an animal could help the farmers with proper feeding, monitoring growth and efficient health care of the animals. However, smallholder farmers lack resources to measure body weight during marketing, feeding, medical dosage and breeding program (Yakubu, 2009). They do not afford to buy weighing scales and for this reason, they are unable to maximise their farm production. Therefore, the use of linear body measurements to estimate body weight is the cheapest and easiest way. Moreover, prediction of live body weight from linear body measurement without the use of weighing scales is convenient and practical in rural areas because of limited resources (Nsoso et al., 2003). Based to acquired knowledge, there is inadequate information on the prediction of body weight using linear body measurement traits in Boer goats raised in farm Tivolie of Limpopo province of South Africa. This study aimed to give farmers farming with Boer goats the knowledge on how to determine the bodyweight without a weighing scale. Hence, the objectives of the study were: (1) Examine the correlation between body weight and linear body measurement traits including body length, cannon bone circumference, ear length, head width, heart girth, rump height and rump width of Boer goats, (2) establish a model for the prediction of body weight from linear body measurement traits of Boer goats.

\section{Materials and Methods}

\section{Study Area and Animal Management}

The study, known as Pieter Smith Boer goat stud, was conducted at Tivolie farm (Fig. 1) situated in Alldays, Blouberg local municipality in the Limpopo province, 
South Africa. A total of 72 Boer goats from the age of one to five were used. The goats were kept inside kraals during the night where water was provided, during the day they could move around the farm, graze and feed on what was available in the farm. They received routine inspection and dipping for herd health management. The goats were kept inside kraals during the night where water was provided. The animals were in an upright position with their head elevated and weight on all four feet without body movement when all the body measurement traits were taken. A measuring tape was used to measure BL, $\mathrm{BD}, \mathrm{CC}, \mathrm{HL}, \mathrm{RG}, \mathrm{RH}$ and RW, while weighing scale was used to measure the body weight. Physical restraints were sometimes applied to limit movement.

\section{Measurements of Linear Body Measurement Traits}

Tape measurement and ruler were used to collect linear body measurement traits including Body Length (BL), cannon Bone Circumference (CC), Ear Length (EL), Head Width (HW), Heart Girth (HG), Rump Height (RH) and Rump Width (RW). The body traits were measured as explained by Yakubu (2009). Briefly, Body Length (BL) was measured diagonally from the lateral tuberosity on the scapula to the pin-bone. Cannon Circumference (CC) was measured as the smallest circumference of the foreleg; Ear Length (EL), was measured as the distance from the point of attachment to the tip of the ear; Head Width (HW), was measured between the roots of the horns and the nuchal crest; Heart Girth (HG), was measured at the most dorsal point of the chest in line with the elbow and hence bisecting the chest at the approximate position of the heart; Rump Height $(\mathrm{RH})$, was measured straight up from the ground to the top of the pelvic girdle and Rump Width (RW), was measured as the distance between the two tuber coxae. One person took all the measurements to avoid individual differences.

\section{Statistical analysis}

Statistical Analysis System version 9.4 (SAS, 2019) software was employed for data analysis. Descriptive statistics was computed for all the measured traits. Pearson's correlation was employed to examine the relationship between measured traits. Simple linear regression was employed to predict body weight from body measurement traits. Probability of 5\% was used for significant and $1 \%$ for highly significant between traits. The following simple linear regression model was used:

$$
Y=a+b x
$$

Where:

$\mathrm{Y}=$ Dependent variable

$\mathrm{a}=$ Intercept

$$
\begin{aligned}
\mathrm{b}= & \text { Regression coefficient } \\
\mathrm{x}= & \text { Independent variable(s) (BL, BD, CC, HL, RG, RH } \\
& \text { and } \mathrm{RW})
\end{aligned}
$$

Coefficient of determination $\left(\mathrm{R}^{2}\right)$ and Mean Square Error (MSE) were used to choose the best-fit model for the estimation of bodyweight

\section{Results}

\section{Descriptive Statistics}

Table 1 Summarises statistics for the bodyweight and some linear body measurements of Boer goats does. The results revealed that the Boer goats does had high heart girth $(90.24 \pm 1.45)$, followed by body length $(81.71 \pm 1.20)$. However, they had lower cannon

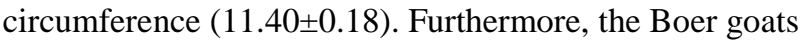
does had an average bodyweight of $59.46 \mathrm{~kg}$.

Table 2. Summarises the statistics for the bodyweight and some linear body measurements of Boer goat bucks. Boer goat bucks also had high heart girth (103.64 \pm 2.00$)$, followed by body length $(97.00 \pm 2.00)$. However, they had a low canon circumference $(15.00 \pm 0.43)$. The Boer goat bucks had an average bodyweight of $100.80 \mathrm{~kg}$.

\section{Phenotypic Correlations Between Body Weight and Linear Body Measurement Traits}

Pearson correlation results (Table 3 ) indicated that BW in Boer goat does had a positive highly remarkable association $(\mathrm{P}<0.01)$ with $\mathrm{BL}, \mathrm{HG}, \mathrm{RH}, \mathrm{CC}$ and $\mathrm{HW}$. The findings in bucks revealed that $\mathrm{BW}$ had a positive highly statistical correlation $(\mathrm{P}<0.01)$ with $\mathrm{BL}, \mathrm{HG}, \mathrm{RH}$ and $\mathrm{HW}$, as well as a positive statistical correlation $(\mathrm{P}<0.05)$ with $\mathrm{RW}$ and $\mathrm{CC}$ and a negative statistical correlation $(\mathrm{P}<0.05)$ with EL.

\section{Effect of Body Length on Bodyweight}

Simple linear regression analysis between bodyweight and body length as presented in Table 4. The regression outcomes showed that there was a positive and linear association among bodyweight and body length. In does, the results recognised a positive highly remarkable association between bodyweight and body length $\left(\mathrm{r}=0.86^{* *}\right)$ with a coefficient of determination $\left(\mathrm{R}^{2}\right)$ of 0.74 and Mean Square Error (MSE) of 92.81. The outcomes showed that body length described about $74 \%$ of the variation in the bodyweight of does. The linear regression equation (Fig. 2A) was established as follows:

$$
B W=-85.20+1.80 B L
$$

Where:

$$
\begin{aligned}
\mathrm{BW} & =\text { Body weight } \\
\mathrm{BL} & =\text { Body Length } \\
-85.20 & =\text { Constant } \\
1.80 & =\text { Regression coefficient of body length }
\end{aligned}
$$


The regression model of body length in does showed that increasing one centimetre $(1 \mathrm{~cm})$ of body length will increase body weight by 2 kilograms $(\mathrm{kg})$. In bucks, the results showed a positive highly statistical correlation between body weight and body length $\left(\mathrm{r}=0.62^{* *}\right)$ with $\mathrm{R}^{2}=0.38$ and mean MSE $=26.55$. The results indicated that body length described about $38 \%$ of the difference in the bodyweight of bucks. The linear regression equation (Fig. 2B) was recognised as follows:

$$
B W=-16.30+1.21 B L
$$

Where:

$$
\begin{aligned}
\mathrm{BW} & =\text { Body Weight } \\
\mathrm{BL} & =\text { Body Length } \\
-12.30 & =\text { Constant } \\
1.21 & =\text { regression coefficient of body length }
\end{aligned}
$$

The regression model of body length in bucks showed that increasing the body length by $1 \mathrm{~cm}$ will increase body weight by $1.21 \mathrm{~kg}$.

\section{Effect of Hearth Girth on Body Weight}

Simple linear regression analysis between body weight and as shown in Table 5. In does, the results showed a positive highly statistical correlation between body weight and heart girth $\left(\mathrm{r}=0.89^{* *}\right)$ with $\mathrm{R}^{2}=0.80$ and MSE $=74.40$. The findings revealed that heart girth explained about $80 \%$ of the variation in the bodyweight of does. The linear regression equation (Fig. 2A) was established as follows:

$$
B W=-77.15+1.51 H G
$$

Where:

$$
\begin{aligned}
\mathrm{BW} & =\text { Body Weight } \\
\mathrm{HG} & =\text { Heart Girth } \\
-77.15 & =\text { Constant } \\
1.51 & =\text { Regression coefficient of heart girth }
\end{aligned}
$$

The regression model of heart girth in does showed that increasing hearth girth by $1 \mathrm{~cm}$ will increase body weight by 1.00 kilo grams $(\mathrm{kg})$. The findings in bucks revealed a positive highly remarkable relationship between body weight and heart girth $(r=0.83 * *)$ with $\mathrm{R}^{2}=0.68$ and MSE $=64.93$. The outcomes showed that heart girth described about $68 \%$ of the variation in the bodyweight of bucks. The linear regression equation (Fig. 2B) was recognised as follows:

$$
B W=-60.80+1.56 H G
$$

Where:

$$
\mathrm{BW}=\text { Body Weight }
$$$$
\mathrm{HG}=\text { Heart Girth }
$$

$$
\begin{aligned}
& -60.80=\text { Constant } \\
& 1.56=\text { Regression coefficient of heart girth }
\end{aligned}
$$

The regression model of heart girth in bucks showed that increasing heart girth by $1 \mathrm{~cm}$ will increase body weight by 1.56 .

\section{Effect of Rump Height on Body Weight}

Simple linear regression analysis between body weight and rump height as shown in Table 6. The findings in does disclosed a positive highly remarkable relationship $(\mathrm{P}<0.01)$ between bodyweight and rump height with $\mathrm{R}^{2}=0.56$ ) and $\mathrm{MSE}=157.20$. The findings discovered that rump height described about $56 \%$ of the differences in the bodyweight of does. The linear regression equation (Fig. 3A) was established as follows:

$$
B W=-74.00+2.04 R H
$$

Where:

$$
\begin{array}{lll}
\mathrm{BW} & = & \text { Body Weight } \\
\mathrm{RH} & = & \text { Rump Height } \\
-74.00= & \text { Constant } \\
2.04= & \text { Regression coefficient of rump height }
\end{array}
$$

The regression model of rump height in does displayed that an increase of $1 \mathrm{~cm}$ in rump height will increase body weight by $2.04 \mathrm{~kg}$. In bucks, the results disclosed a positive highly statistical correlation $(\mathrm{P}<0.01)$ between body weight and rump height $(\mathrm{r}=0.56 * *)$ with $\mathrm{R}^{2}=0.31$ and MSE $=142.07$. The results showed that rump height explained about $31 \%$ of the variation in the bodyweight of bucks. The linear regression equation (Fig. 3B) was established as follows:

$$
B W=-31.30+1.72 R H
$$

Where:

$$
\begin{array}{ll}
\mathrm{BW} & =\text { Body Weight } \\
\mathrm{RH} & =\text { Rump Height } \\
-31.20 & =\text { Constant } \\
1.72 & =\text { Regression coefficient of rump height }
\end{array}
$$

The regression model of rump height in bucks showed that by increasing $1 \mathrm{~cm}$ of rump height will increase body weight by $1.72 \mathrm{~kg}$.

\section{Effect of Rump Width on Body Weight}

Simple linear regression analysis between bodyweight and rump width is shown in Table 7 . The findings in does showed a positive remarkable association between bodyweight and rump width $(\mathrm{r}=0.42 *)$ with $\mathrm{R}^{2}=0.17$ and $\mathrm{MSE}=293.67$. The outcomes discovered that rump width described about $17 \%$ of the difference in the body weight of does. The linear regression equation (Fig. 4A) was established as follows: 


$$
B W=11.00+2.32 R W
$$

Where:

$\begin{array}{lll}\mathrm{BW} & = & \text { Body Weight } \\ \mathrm{RW} & = & \text { Rump Width } \\ 11.00 & = & \text { Constant } \\ 2.32 & = & \text { Regression coefficient of rump width }\end{array}$

The regression model of rump width of does displayed that by increasing $1 \mathrm{~cm}$ of rump width will improve body weight by $2.32 \mathrm{~kg}$. In bucks, the results disclosed a remarkable association $(\mathrm{P}<0.05)$ between body weight and rump width $\left(\mathrm{r}=0.31^{*}\right)$ with $\mathrm{R}^{2}=0.09$ and $\mathrm{MSE}=186.21$. The outcomes showed that rump width described about $9 \%$ of the difference in the bodyweight of bucks. The linear regression equation (Fig. 4B) was established as follows:

$$
B W=42.45+2.23 R W
$$

Where:

$$
\begin{aligned}
& \mathrm{BW}=\text { Body Weight } \\
& \mathrm{RW}=\text { Rump Width } \\
& 42.45=\text { Constant } \\
& 2.23=\text { Regression coefficient of rump width }
\end{aligned}
$$

The regression model of rump width in bucks displayed that by increasing $1 \mathrm{~cm}$ of rump width will improve body weight by $2.32 \mathrm{~kg}$.

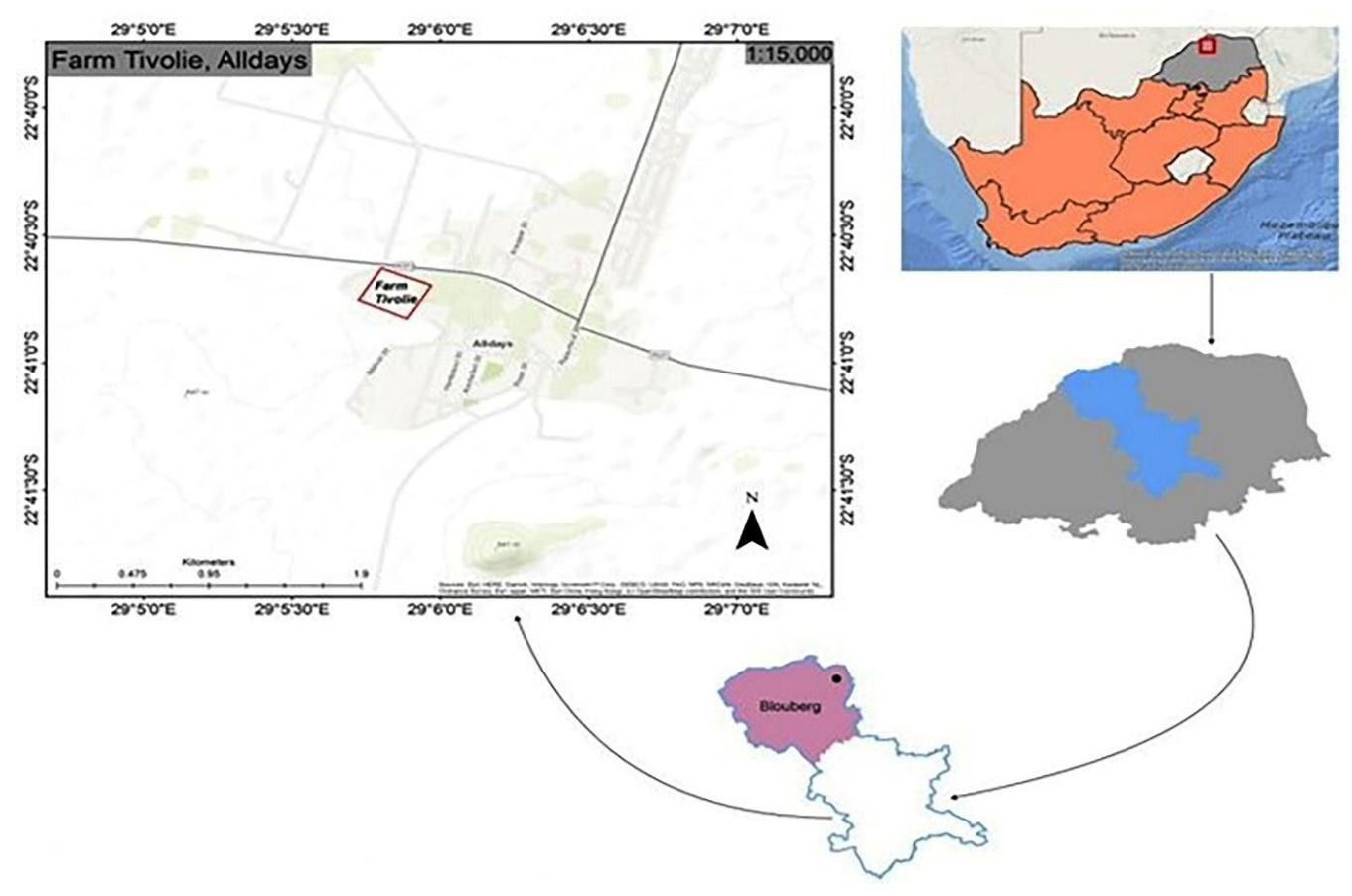

Fig. 1: Map of the study area
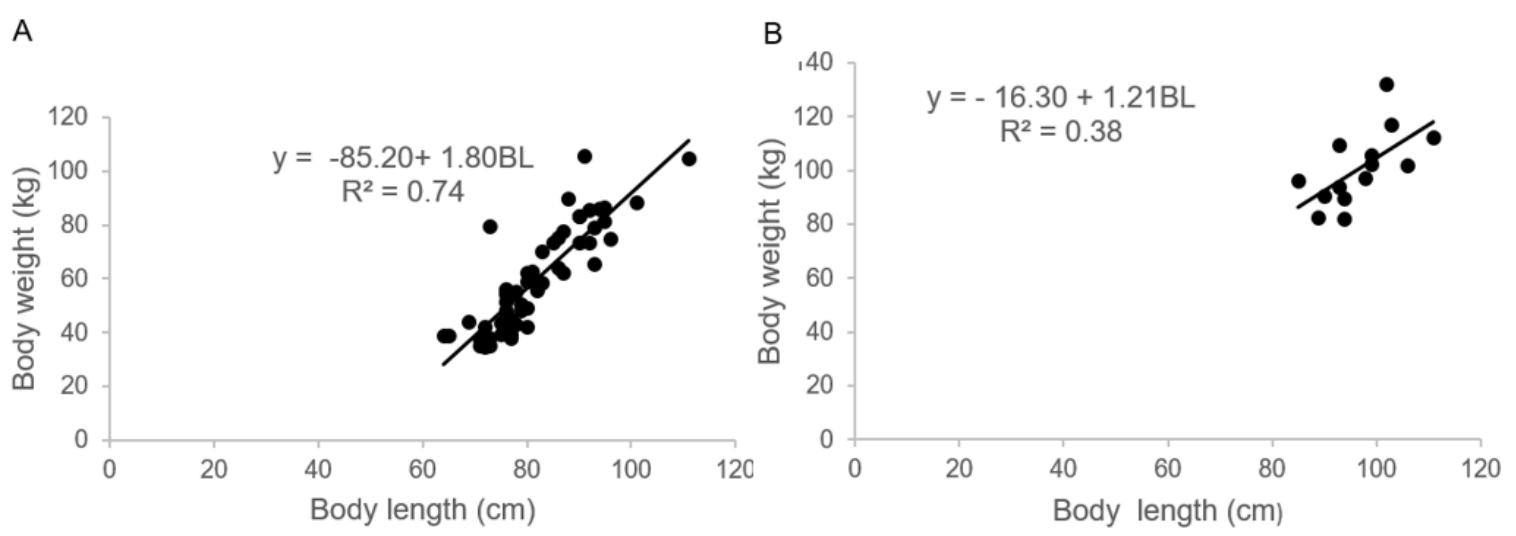

Fig. 2: Effect of body weight on body length. (B) Bucks. BW: Body Weight; BL: Body Length; R2: Coefficient of determination 


$$
\text { A }
$$

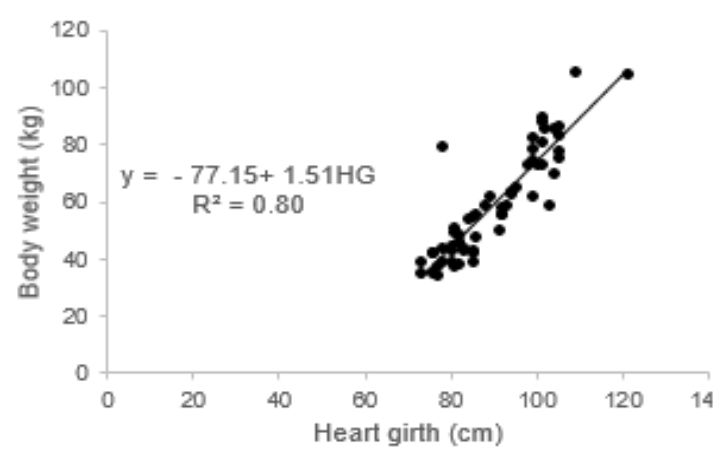

\section{B}

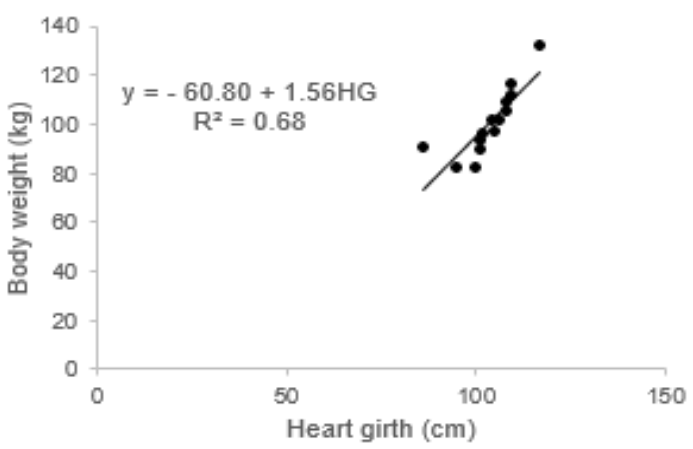

Fig. 2: Effect of body weight on heart girth. (A) Does. B) Bucks. BW: Body Weight; HG: Heart Girth; R2: Coefficient of determination
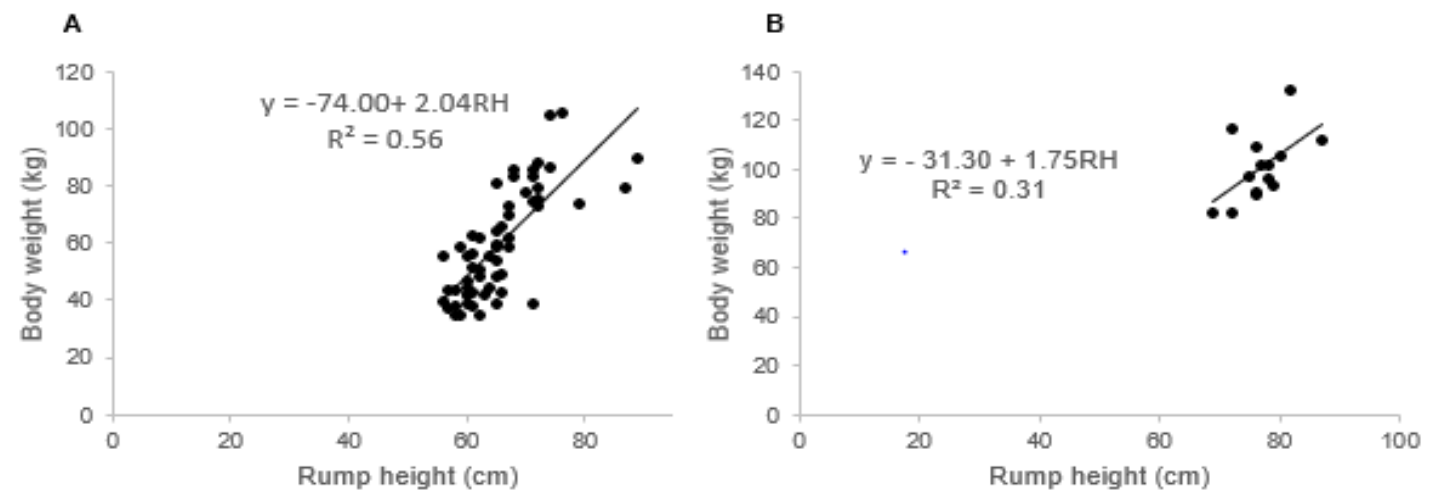

Fig. 3: Effect of body weight on rump height. (A) Does. (B) Bucks. BW: Body Weight; RH: Rump Height; R2: Coefficient of determination
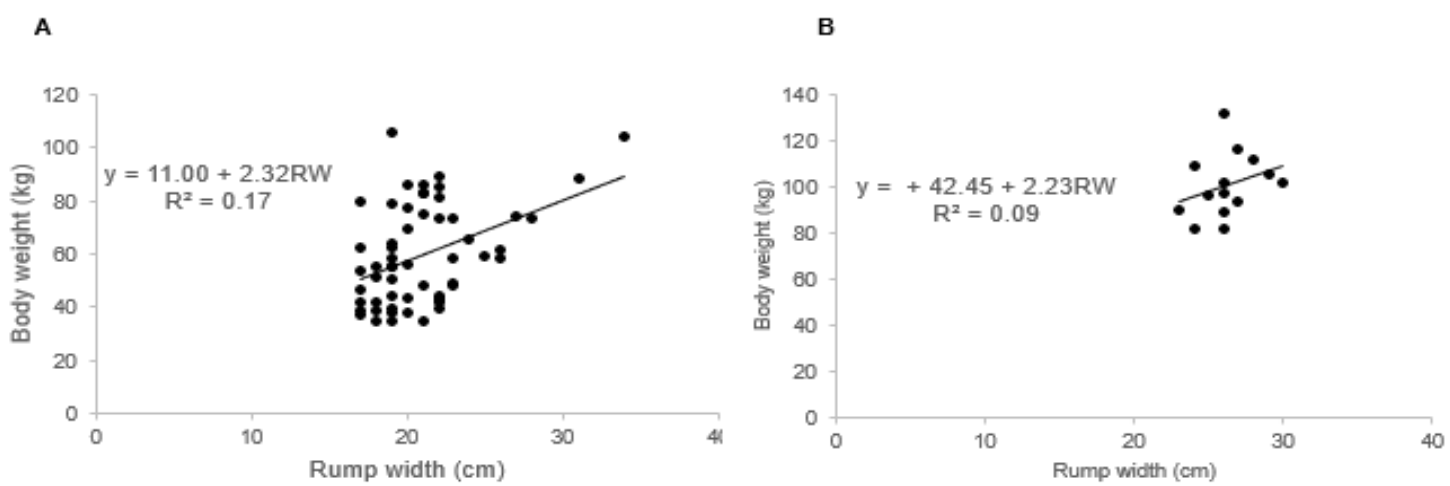

Fig. 4: Effect of body weight on rump width. (A) Does. (B) Bucks. BW: Body Weight; RW: Rump Width; R2: Coefficient of determination

Table 1: Descriptive statistics for body weight and body measurements traits of Boer goat does

\begin{tabular}{llll}
\hline Traits & Mean \pm SE & SD & CV (\%) \\
\hline BW $(\mathrm{kg})$ & $59.46 \pm 2.46$ & 18.74 & 0.31 \\
BL $(\mathrm{cm})$ & $81.71 \pm 1.20$ & 9.12 & 0.11 \\
HG $(\mathrm{cm})$ & $90.24 \pm 1.45$ & 11.02 & 0.12 \\
RH $(\mathrm{cm})$ & $65.52 \pm 0.91$ & 7.00 & 0.11 \\
RW $(\mathrm{cm})$ & $21.55 \pm 0.45$ & 3.42 & 0.16 \\
EL $(\mathrm{cm})$ & $22.10 \pm 0.34$ & 2.56 & 0.12 \\
CC $(\mathrm{cm})$ & $11.40 \pm 0.18$ & 1.37 & 0.12 \\
HW $(\mathrm{cm})$ & $15.00 \pm 0.20$ & 1.50 & 0.10 \\
\hline
\end{tabular}

SE: Standard Error, SD: Standard Deviation, CV: Coefficient of Variance, BW: Body Weight, BL: Body Length, HG: Heart Girth, RH: Rump height, RW: Rump Width, EL: Ear Length, CC: Cannon Circumference, HW: Head Width 
Table 2: Descriptive statistics for body weight and body measurements traits of Boer goat bucks.

\begin{tabular}{llll}
\hline Traits & Mean \pm SE & SD & CV (\%) \\
\hline BW $(\mathrm{kg})$ & $100.80 \pm 3.70$ & 13.80 & 0.14 \\
BL $(\mathrm{cm})$ & $97.00 \pm 2.00$ & 7.09 & 0.73 \\
HG $(\mathrm{cm})$ & $103.64 \pm 2.00$ & 7.32 & 0.07 \\
RH $(\mathrm{cm})$ & $76.92 \pm 1.20$ & 4.50 & 0.06 \\
RW $(\mathrm{cm})$ & $26.21 \pm 0.51$ & 1.92 & 0.07 \\
EL $(\mathrm{cm})$ & $23.00 \pm 0.57$ & 2.13 & 0.09 \\
CC $(\mathrm{cm})$ & $15.00 \pm 0.43$ & 1.61 & 0.10 \\
HW $(\mathrm{cm})$ & $18.50 \pm 0.55$ & 2.07 & 0.11 \\
\hline
\end{tabular}

SE: Standard Error, SD: Standard Deviation, CV: Coefficient of Variance, BW: Body Weight, BL: Body Length, HG: Heart Girth, RH: Rump Hight, RW: Rump Width, EL: Ear Length, CC: Cannon Circumference, HW: Head Width

Table 3: Pearson association between body weight and linear body measurement traits of Boer goat bucks above diagonal and Boer goat does below diagonal

\begin{tabular}{|c|c|c|c|c|c|c|c|c|}
\hline Traits & BW & BL & $\mathrm{HG}$ & $\mathrm{RH}$ & RW & EL & $\mathrm{CC}$ & HW \\
\hline BW (kg) & & $0.62 * *$ & $0.83 * *$ & $0.56 * *$ & $0.31^{\mathrm{ns}}$ & $-0.25^{*}$ & $0.36^{*}$ & $0.51 * *$ \\
\hline $\mathrm{BL}(\mathrm{cm})$ & $0.86^{* *}$ & & $0.62 * *$ & $0.52 * *$ & $0.51 * *$ & $0.17^{\mathrm{ns}}$ & $0.71 * *$ & $0.63 * *$ \\
\hline $\mathrm{HG}(\mathrm{cm})$ & $0.89 * *$ & $0.90 * *$ & & $0.48^{*}$ & $0.48^{*}$ & $-0.16^{\mathrm{ns}}$ & $0.47 *$ & $0.39^{*}$ \\
\hline RH (cm) & $0.75 * *$ & $0.53 * *$ & $0.45 * *$ & & $0.39^{*}$ & $0.08^{\mathrm{ns}}$ & $0.41^{*}$ & $0.61 * *$ \\
\hline $\mathrm{RW}(\mathrm{cm})$ & $0.42 *$ & $0.67 * *$ & $0.47 * *$ & $0.29 *$ & & $0.04^{\mathrm{ns}}$ & $0.44^{*}$ & $0.47 *$ \\
\hline $\mathrm{EL}(\mathrm{cm})$ & $0.49 *$ & $0.59 * *$ & $0.48 * *$ & $0.40 *$ & $0.68 * *$ & & $0.50 * *$ & $0.06^{\mathrm{ns}}$ \\
\hline $\mathrm{CC}(\mathrm{cm})$ & $0.58 * *$ & $0.65 * *$ & $0.52 * *$ & $0.44 *$ & $0.63^{* *}$ & $0.55^{* *}$ & & $0.28^{*}$ \\
\hline $\mathrm{HW}(\mathrm{cm})$ & $0.65 * *$ & $0.49 * *$ & $0.48 *$ & $0.53 * *$ & $0.12^{\mathrm{ns}}$ & $0.18^{\mathrm{ns}}$ & $0.14^{\mathrm{ns}}$ & \\
\hline
\end{tabular}

**. Correlation is significant at the 0.01 level: *. Correlation is significant at the 0.05 level: Ns non-significance BW: Bodyweight, BL: Body Length, HG: Heart Girth, RH: Rump Height, RW: Rump Width, EL: Ear Length, CC: Cannon Circumference, HW: HEAD width

Table 4: Regression between bodyweight and body length

\begin{tabular}{lllllll}
\hline Source & Sum of squares & Df & Mean square & $\mathrm{R}$ & $\mathrm{R}^{2}$ & Adjusted R $^{2}$ \\
\hline Does & & & & & \\
Regression & 14821.13 & 1 & 14821.13 & $0.86^{* *}$ & 0.74 & 0.73 \\
Residual & 5197.20 & 56 & 92.81 & & & \\
Total & 20018.34 & 57 & & & $0.62^{* *}$ & 0.38 \\
Bucks & & & & & 0.33 \\
Regression & 955.38 & 1 & 955.38 & & \\
Residual & 1518.70 & 12 & 126.55 & & \\
Total & 2474.08 & 13 & & & &
\end{tabular}

DF: Degree of Freedom; R: Correlation coefficient; $\mathrm{R}^{2}$ : Coefficient of determination; Adjusted $\mathrm{R}^{2}$ : Adjusted coefficient of determination; ** Significant at $\mathrm{p}<0.01$

Table 5: Regression between bodyweight and heart girth

\begin{tabular}{|c|c|c|c|c|c|c|}
\hline Source & Sum of squares & $\mathrm{DF}$ & Mean square & $\mathrm{R}$ & $\mathrm{R}^{2}$ & Adjusted $\mathrm{R}^{2}$ \\
\hline \multicolumn{7}{|l|}{ Does } \\
\hline Regression & 15851.73 & 1 & 15851.73 & $0.89 * *$ & 0.80 & 0.79 \\
\hline Residual & 4166.61 & 56 & 74.40 & & & \\
\hline Total & 20018.34 & 57 & & & & \\
\hline \multicolumn{7}{|l|}{ Bucks } \\
\hline Regression & 1694.90 & 1 & 1694.90 & $0.83 * *$ & 0.68 & 0.65 \\
\hline Residual & 779.18 & 12 & 64.93 & & & \\
\hline Total & 2474.08 & 13 & & & & \\
\hline
\end{tabular}

DF: Degree of Freedom; R: Correlation coefficient; $\mathrm{R}^{2}$ : Coefficient of determination; Adjusted $\mathrm{R}^{2}$ : Adjusted coefficient of determination; ** Significant at $\mathrm{p}<0.01$ 
Table 6: Regression between bodyweight and rump height

\begin{tabular}{|c|c|c|c|c|c|c|}
\hline Source & Sum of squares & Df & Mean square & $\mathrm{R}$ & $\mathrm{R}^{2}$ & Adjusted $\mathrm{R}^{2}$ \\
\hline \multicolumn{7}{|l|}{ Does } \\
\hline Regression & 11215.26 & 1 & 11215.26 & $0.75^{* *}$ & 0.56 & 0.55 \\
\hline Residual & 8803.08 & 56 & 157.20 & & & \\
\hline Total & 20018.34 & 57 & & & & \\
\hline \multicolumn{7}{|l|}{ Bucks } \\
\hline Regression & 769.16 & 1 & 769.16 & $0.56^{*}$ & 0.31 & 0.25 \\
\hline Residual & 1704.92 & 12 & 142.07 & & & \\
\hline Total & 2474.08 & 13 & & & & \\
\hline
\end{tabular}

DF: Degree of Freedom; R: Correlation Coefficient; $\mathrm{R}^{2}$ : Coefficient of determination; Adjusted $\mathrm{R}^{2}$ : Adjusted coefficient of determination; **Significant at $\mathrm{p}<0.01 ; *$ Significant at $\mathrm{p}<0.05$

Table 7: Regression between body weight and rump width

\begin{tabular}{|c|c|c|c|c|c|c|}
\hline Source & Sum of squares & DF & Mean square & $\mathrm{R}$ & $\mathrm{R}^{2}$ & Adjusted $\mathrm{R}^{2}$ \\
\hline \multicolumn{7}{|l|}{ Does } \\
\hline Regression & 3572.55 & 1 & 3572.55 & $0.42 *$ & 0.17 & 0.16 \\
\hline Residual & 16445.79 & 56 & 293.67 & & & \\
\hline Total & 20018.34 & 57 & & & & \\
\hline \multicolumn{7}{|l|}{ Bucks } \\
\hline Regression & 239.51 & 1 & 239.51 & $0.31^{*}$ & 0.09 & 0.02 \\
\hline Residual & 2234.57 & 12 & 186.21 & & & \\
\hline Total & 2474.08 & 13 & & & & \\
\hline
\end{tabular}

DF: Degree of Freedom; R: Correlation coefficient; $\mathrm{R}^{2}$ : Coefficient of determination; Adjusted $\mathrm{R}^{2}$ : Adjusted coefficient of determination; ** Significant at $\mathrm{p}<0.01$

\section{Effect of Ear Length on Body Weight}

Simple linear regression analysis between body weight and ear length as shown in Table 8. In does, the outcomes revealed a positive remarkable association $(\mathrm{P}<0.05)$ between body weight and rump width, with $\mathrm{R}^{2}=0.23$ and MSE $=272.42$. The findings discovered that ear length described about $23 \%$ of the disparity in the body weight of does. The linear regression equation (Fig. 5A) was established as follows:

$$
B W=-19.00+3.54 E L
$$

Where:

$$
\begin{aligned}
\mathrm{BW} & =\text { Body Weight } \\
\mathrm{EL} & =\text { Ear Length } \\
-19.00 & =\text { Constant } \\
3.54 & =\text { Regression coefficient of ear length }
\end{aligned}
$$

The regression model of ear length in does displayed that an increase of $1 \mathrm{~cm}$ in ear length will increase body weight by $3.54 \mathrm{~kg}$. The results in bucks displayed a negative remarkable correlation $(\mathrm{P}<0.05)$ between body weight and ear length, with $\mathrm{R}^{2}=0.06$ and MSE $=193.22$. The results showed that ear length described about $6 \%$ of the difference in the bodyweight of bucks. The linear regression equation (Fig. 5B) was established as follows:

$$
B W=137.91-1.62 E L
$$

Where:

$$
\begin{array}{ll}
\mathrm{BW} & =\text { Body Weight } \\
\mathrm{EL} & =\text { Ear Length }
\end{array}
$$

$137.91=$ constant

$-1.62=$ regression coefficient of ear length

The regression model of ear length in bucks revealed that an increase of $1 \mathrm{~cm}$ in ear length will decrease body weight by $1.62 \mathrm{~kg}$.

\section{Effect of Cannon Circumference on Body Weight}

Simple linear regression analysis between bodyweight and cannon circumference as presented in Table 9. The outcomes in does disclosed a positive highly remarkable relationship $(\mathrm{P}<0.01)$ between body weight and cannon circumference, with $\mathrm{R}^{2}=0.33$ and $\mathrm{MSE}=238.79$. The findings showed that cannon circumference described about $33 \%$ of the disparity in the bodyweight of does. The linear regression equation (Fig. 6A) was established as follows:

$$
B W=-30.00+8.00 C C
$$

Where:

$\mathrm{BW}=$ Body Weight

$\mathrm{CC}=$ Cannon Circumference

$-30.00=$ Constant

$8.00=$ Regression coefficient of cannon circumference

The regression model of cannon circumference of does showed that increasing cannon circumference by $1 \mathrm{~cm}$ will increase body weight by $8.00 \mathrm{~kg}$. The results in bucks revealed a remarkable association $(\mathrm{P}<0.05)$ between 
bodyweight and cannon circumference with $\mathrm{R}^{2}=0.12$ and MSE $=179.71$. The outcomes displayed that cannon circumference described about $12 \%$ of the disparity in the body weight of bucks. The linear regression equation (Fig. 6B) was established as follows:

$$
B W=55.00+3.01 C C
$$

Where:

$\mathrm{BW}=$ Body weight

$\mathrm{CC}=$ Cannon Circumference

$55.00=$ constant

$3.01=$ regression coefficient of cannon circumference

The regression model of cannon circumference showed that by increasing $1 \mathrm{~cm}$ of cannon circumference will increase body weight by $3.01 \mathrm{~kg}$.

\section{Effect of Head width on Body Weight}

Simple linear regression analysis between body weight and head width as presented in Table 10. The results in does displayed a positive highly remarkable association $(\mathrm{P}<0.01)$ between body weight and head width $\left(\mathrm{r}=0.65^{* *}\right)$ with $\mathrm{R}^{2}=0.42$ and MSE $=206.09$. The outcomes discovered that head width described about $42 \%$ of difference in the body weight of does. The linear regression equation (Fig. 7A) was established as follows:

$$
B W=-60.74+8.10 H W
$$

$$
\begin{aligned}
& \text { Where; } \\
& \mathrm{BW}=\text { Body Weight } \\
& \mathrm{HW}=\text { Head Width } \\
& -60.74=\text { Constant } \\
& 8.10=\text { Regression coefficient of head width }
\end{aligned}
$$

The regression model of head width in does showed that by increasing $1 \mathrm{~cm}$ of head width will increase body weight by $8.10 \mathrm{~kg}$. The outcomes in bucks disclosed a positive highly remarkable association $(\mathrm{P}<0.01)$ between body weight and head width with $\mathrm{R}^{2}=0.26$ and MSE $=152.05$. The outcomes showed that head width described about $26 \%$ of the disparity in the bodyweight of bucks. The linear regression equation (Fig. 7B) was established as follows:

$$
B W=37.51+3.42 H W
$$

\begin{tabular}{|c|c|c|c|c|c|c|}
\hline Source & Sum of squares & DF & Mean square & $\mathrm{R}$ & $\mathrm{R}^{2}$ & Adjusted $\mathrm{R}^{2}$ \\
\hline \multicolumn{7}{|l|}{ Does } \\
\hline Regression & 4762.90 & 1 & 4762.90 & $0.49 *$ & 0.23 & 0.22 \\
\hline Residual & 15255.43 & 56 & 272.42 & & & \\
\hline Total & 20018.34 & 57 & & & & \\
\hline \multicolumn{7}{|l|}{ Bucks } \\
\hline Regression & 155.35 & 1 & 155.35 & $-0.25^{*}$ & 0.06 & -0.01 \\
\hline Residual & 2318.73 & 12 & 193.22 & & & \\
\hline Total & 2474.08 & 13 & & & & \\
\hline
\end{tabular}

Where:

$$
\begin{aligned}
& \mathrm{BW}=\text { Body Weight } \\
& \mathrm{HW}=\text { Head Width } \\
& 37.51=\text { Constant } \\
& 3.42=\text { Regression coefficient of head width }
\end{aligned}
$$

\begin{tabular}{|c|c|c|c|c|c|c|}
\hline Source & Sum of squares & DF & Mean square & $\mathrm{R}$ & $\mathrm{R}^{2}$ & Adjusted $\mathrm{R}^{2}$ \\
\hline \multicolumn{7}{|l|}{ Does } \\
\hline Regression & 6645.62 & 1 & 6645.62 & $0.58 * *$ & 0.33 & 0.32 \\
\hline Residual & 13372.71 & 56 & 238.79 & & & \\
\hline Total & 20018.33 & 57 & & & & \\
\hline \multicolumn{7}{|l|}{ Bucks } \\
\hline Regression & 317.50 & 1 & 317.50 & $0.36^{*}$ & 0.12 & 0.05 \\
\hline Residual & 2156.58 & 12 & 179.71 & & & \\
\hline Total & 2474.08 & 13 & & & & \\
\hline
\end{tabular}

The regression model of head width in bucks showed that increasing head width by $1 \mathrm{~cm}$ will increase body weight by $3.42 \mathrm{~kg}$

Table 8: Regression between body weight and ear length

DF: Degree of Freedom; R: Correlation coefficient; $\mathrm{R}^{2}$ : Coefficient of determination; Adjusted $\mathrm{R}^{2}$ : Adjusted coefficient of determination; *Significant at $\mathrm{p}<0.05$

Table 9: Regression between bodyweight and cannon circumference

DF: Degree of Freedom; R: Correlation coefficient; $\mathrm{R}^{2}$ : Coefficient of determination; Adjusted $\mathrm{R}^{2}$ : Adjusted coefficient of determination; **Significant at $\mathrm{p}<0.01$, *Significant at $\mathrm{p}<0.05$ 
Table 10: Regression between body weight and head width

\begin{tabular}{|c|c|c|c|c|c|c|}
\hline Source & Sum of squares & DF & Mean square & $\mathrm{R}$ & $\mathrm{R}^{2}$ & Adjusted $\mathrm{R}^{2}$ \\
\hline \multicolumn{7}{|l|}{ Does } \\
\hline Regression & 8431.56 & 1 & 8431.56 & $0.65 * *$ & 0.42 & 0.41 \\
\hline Residual & 11586.77 & 56 & 206.90 & & & \\
\hline Total & 20018.33 & 57 & & & & \\
\hline \multicolumn{7}{|l|}{ Bucks } \\
\hline Regression & 649.42 & 1 & 649.42 & $0.51 * *$ & 0.26 & 0.20 \\
\hline Residual & 1824.66 & 12 & 152.05 & & & \\
\hline Total & 2474.08 & 13 & & & & \\
\hline
\end{tabular}

Df: Degree of Freedom; R: Correlation coefficient; $\mathrm{R}^{2}$ : Coefficient of determination; Adjusted $\mathrm{R}^{2}$ : Adjusted coefficient of determination; **Significant at $\mathrm{p}<0.01$
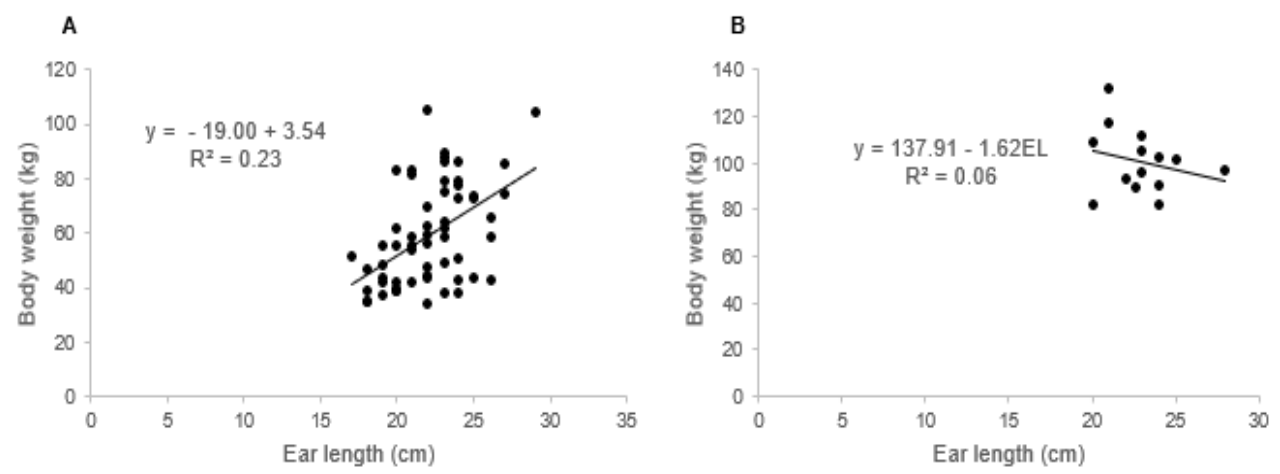

Fig. 5: Effect of body weight on ear length. (A) Does. (B) Bucks. BW: Body Weight; EL: Ear Length; R2: Coefficient of determination
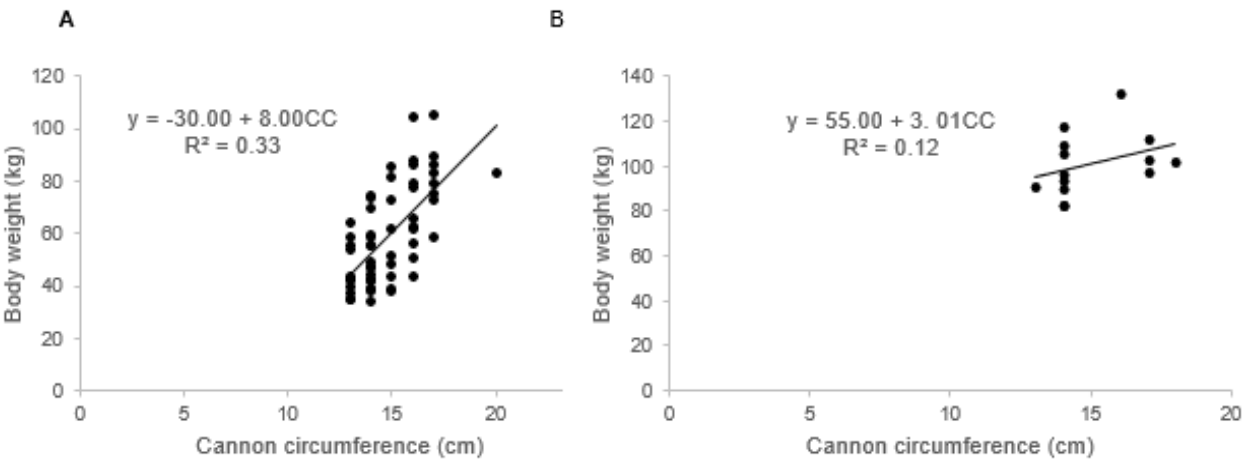

Fig. 6: Effect of body weight on cannon circumference. (A) Does. (B) Bucks. BW: Body Weight; CC: Cannon Circumference; R2: Coefficient of determination
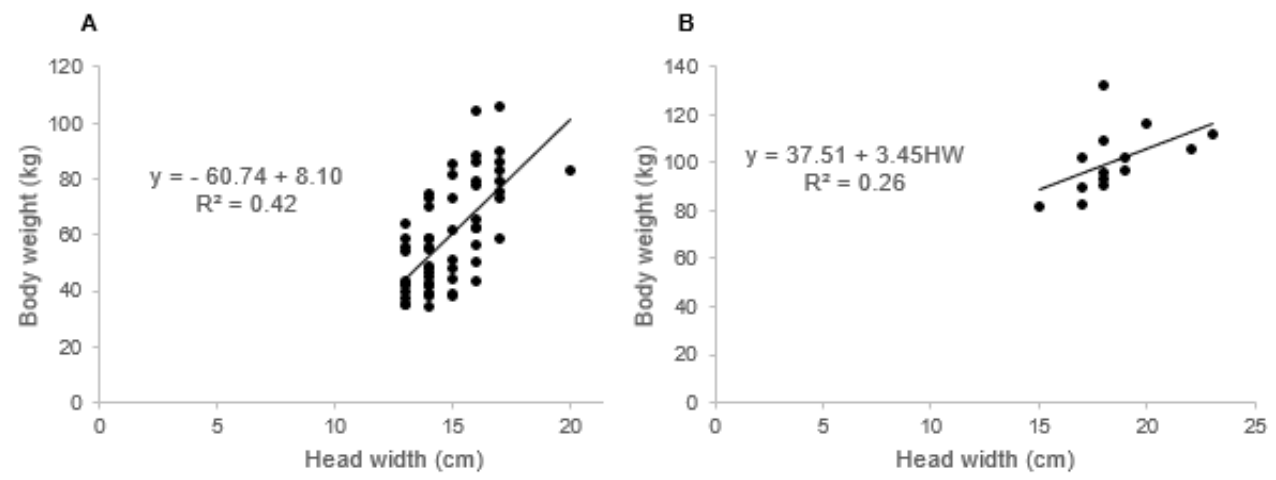

Fig. 7: Effect of body weight on head width. (A) Does. (B) Bucks. BW: Body Weight; HW: Head Width; R2: Coefficient of determination 


\section{Discussion}

In animal breeding, some linear body measurement traits are recognised as predictors of body weight in different goat breeds such as South African non-descript goat (Norris et al., 2015; Tyasi et al., 2020). We firstly examined the relationship among body weight and linear body measurement traits of Boer goats. In does, the results showed that there was an association among body weight and all the measured body measurements traits. However, some body measurements traits did not show any relationship amongst themselves. The association between body weight and heart girth being the highest, followed by the correlation between body weight and body length and the association between body and rump width being the lowest. In bucks, the findings revealed that there was an association between body weight and some body measurements traits. An association was found between body weight and body length, heart girth, rump height and head width. A similar study by Hagos (2016) reported that there was a relationship between body weight, heart girth, body length and rump height in Begait Goats. However, Fahim et al. (2013) reported that there is no significance between body weight and ear length in Rohilkhand local goats. The differences might be due to breed and environmental differences. Based on the results from the current study body measurement traits can be used to predict body weight, which will then be beneficial to farmers with no weighting scales and these body measurement traits may be used in the selection criteria during breeding to enhance body weight in Boer goats. We also employed all the measured linear body measurement traits to develop a model that might be of use to estimate body weight of Boer goats using simple linear regression. Coefficient of determination and mean square error were used to determine the best fitting regression equation. Our regression findings showed that hearth girth had the highest coefficient of determination and low mean square error, followed by a body length in does. Hence, the findings recommend that heart girth and body length had a higher contribution on the bodyweight of does as compared to the other measured linear body measurement traits. In bucks, heart girth had the highest coefficient of determination and low mean square error. Thus, the findings suggest that heart girth had the highest contribution to the bodyweight of bucks. Tyasi et al. (2020) reported in South African non-descript goats that withers height had the highest coefficient of determination in does while rump height had the highest coefficient of determination in bucks. Berhe (2017), indicated that heart girth is the best body trait used to predict live body weight with reasonable accuracy. Temoso et al. (2017) reported that in goats and sheep of communal rangelands in Botswana, heart girth and sternum height had a positive and significant effect on the bodyweight of both bucks and does.

\section{Conclusion}

The current study acknowledged that there is a sex effect on descriptive statistics. Pearson correlation outcomes recommend that there is a connection among body weight and body length, heart girth, rump height, rump width, ear length, cannon circumference and head width of Boer goats. In does, all the studied traits had a remarkable relationship with body weight. In bucks, only body length, heart girth and rump height had a statistical remarkable correlation with body weight. Simple linear regression was also done to assess the effect of linear body measurements traits on the bodyweight of Boer goats. Regression results indicated that heart girth contributes greatly to the bodyweight of both does and bucks of Boer goats.

\section{Acknowledgements}

The authors acknowledge the Tivolie farm manager and farmworkers for their support during data collection. The animal breeding and genetics masters team for their support and motivation throughout the journey. The authors also acknowledge the financial support from the national research foundation (grant number: 121987).

\section{Disclosure Statement}

The authors declare that there is no conflict of interest for this work.

\section{Author's Contributions}

Lebo Trudy Rashijane: Design the study, data collection, wrote the first draft of the manuscript, revise the manuscript and approve the final manuscript.

Vusi G Mbazima: Revise the manuscript and approve the final manuscript.

Thobela Louis Tyasi: Design the study, data collection, data analysis, revise the manuscript and approve the final manuscript.

\section{Ethics}

All processes were completed following the standards and protocols set by the University of Limpopo Animal Research Ethics Committee (AREC) and certificate number is AREC/11/2020: PG.

\section{References}

Atoui, A., Hajejji, Z., Abdennebi, M., Gaddour, A., \& Najari, S. (2017). Environmental factors affecting birth weight of Tunisian local goat population kids. Journal of New Sciences, 38. 
Berhe, W. G. (2017). Relationship and prediction of body weight from morphometric traits in Maefur goat population in Tigray, Northern Ethiopia. J. Biom. Biostat, 8(5), 1-6. doi.org/10.4172/2155-6180.1000370

Cam, M. A., Olfaz, M., \& Soydan, E. (2010). Possibilities of using morphometrics characteristics as a tool for body weight prediction in Turkish Hair Goats (Kilkeci). Asian Journal of Animal and Veterinary Advances, 5(1), 52-59. doi.org/10.3923/ajava.2010.52.59

Fahim, A., Patel, B. H. M., \& Rijasnaz, V. V. (2013). Relationship of body weight with linear body measurements in Rohilkhand local goats. Indian Journal of Animal Research, 47(6), 521-526. https://www.indianjournals.com/ijor.aspx?target=ijo r:ijar $1 \&$ volume $=47 \&$ issue $=6 \&$ article $=010$

Hagos, G. (2016). Estimation of live body weight from the linear body measurements of Begait goats in Western Tigray. Ethiopia. Journal of Natural Sciences Research, 6(9), 23-27.

Monteiro, A., Costa, J. M., \& Lima, M. J. (2017). Goat system productions: Advantages and disadvantages to the animal, environment and farmer. Goat Science, 351-366. doi.org/10.5772/intechopen.70002

Norris, D., Brown, D., Moela, A. K., Selolo, T. C. Mabelebele, M., Ngambi, J. W., \& Tyasi, T. L. (2015). Path coefficient and path analysis of body weight and biometric traits in indigenous goats. Indian Journal of Animal Research, 49(5), 573-578. doi.org/10.18805/ijar.5564
Nsoso, S. J., Aganga, A. A., Moganetsi, B. P., \& Tshwenyane, S. O. (2003). Body weight, body condition score and heart girth in indigenous Tswana goats during the dry and wet seasons in southeast Botswana. Livestock Research for Rural Development, 15(4). https://www.lrrd.cipav.org.co/lrrd15/4/nsos154.htm SAS. (2019). User guide: statistics release 9.4. Statistical Analysis System Institute, Inc., Cary, North Caroline. Shirzeyli, F. H., Lavvaf, A., \& Asadi, A. (2013). Estimation of body weight from body measurements in four breeds of Iranian sheep. Songklanakarin Journal of Science \& Technology, 35(5). http://rdo.psu.ac.th/sjst/journal/35-5/35-5-2.pdf

Temoso, O., Coleman, M., Baker, D., Morley, P., Baleseng, L., Makgekgenene, A., \& Bahta, S. (2017). Using path analysis to predict bodyweight from body measurements of goats and sheep of communal rangelands in Botswana. South African Journal of Animal Science, 47(6), 854-863. doi.org/10.4314/sajas.v47i6.13

Tyasi, T. L., Mathapo, M. C., Mokoena, K., Maluleke, D., Rashijane, L. T., Makgowo, K. M., ... \& Mathye, N. D. (2020). Assessment of relationship between body weight and morphological traits of South African nondescript indigenous goats. J. Anim. Health Prod, $8(1), 32-39$. doi.org/10.17582/journal.aavs/2020/8.4.354.359

Yakubu, A. (2009). Fixing collinearity instability in the estimation of body weight from morpho-biometrical traits of West African Dwarf goats. Trakia J. Sci, 7(2), 61-66. 